\title{
PROJECT FINANCE E COLIGAÇÃO CONTRATUAL: QUALIFICAÇÃO E CONSEQUÊNCIAS JURÍDICAS
}

Dissertação apresentada ao Programa de PósGraduação em Direito da Faculdade de Direito de Ribeirão Preto da Universidade de São Paulo, como requisito parcial para a obtenção do título de Mestre em Ciências, Programa: Direito. Versão original.

Área de Concentração: Desenvolvimento no Estado Democrático de Direito.

Orientador: Prof. Associado Gustavo Saad Diniz

\section{RIBEIRÃO PRETO}




\section{RESUMO}

\section{SILVA, Raphael Andrade. Project Finance e coligação contratual: qualificação e}

consequências jurídicas. 2017. 258 p. Dissertação (Mestrado) - Faculdade de Direito de Ribeirão Preto da Universidade de São Paulo, Ribeirão Preto, 2017.

A presente dissertação se propõe à qualificação do conjunto de contratos celebrados em financiamentos organizados sob a modalidade project finance como verdadeira coligação contratual, apresentando determinadas consequências jurídicas daí decorrentes, bem como sublinhando a correlação positiva entre tal compreensão e o estabelecimento de um panorama institucional adequado, que contribua para o desenvolvimento econômico. Ocupa posição nuclear no estudo o reconhecimento de que os negócios jurídicos concluídos no âmbito de tais programas de financiamento consistem, de fato, em instrumentos aptos a operacionalizar um arranjo de alocação de riscos que reflita a racionalidade econômico-financeira do projeto, garantindo, assim, sua viabilidade. Portanto, muito embora conservem sua autonomia estrutural e desempenhem, cada um deles, sua função econômico-social individual, contribuem, simultaneamente, para a realização de um fim concreto ulterior - operação econômica subjacente -, que coincide com o desenvolvimento e operação do empreendimento financiado. Pretende-se, igualmente, oferecer subsídios para que aqueles que sejam chamados a decidir sobre questões versando a temática abordada o façam de forma crítica e coerente, sem descuidar das motivações, econômicas e jurídicas, que subjazem ao project finance.

Palavras-chave: Project Finance. Coligação contratual. Financiamento de projetos. Contratos coligados. 


\begin{abstract}
SILVA, Raphael Andrade. Project finance and connected contracts: qualification and legal effects. 2017. 258 p. Dissertação (Mestrado) - Faculdade de Direito de Ribeirão Preto da Universidade de São Paulo, Ribeirão Preto, 2017.

This thesis aims to qualify the nexus of contracts entered into in project financings as connected contracts, presenting certain legal effects which hence arise, as well as highlighting the positive correlation between such qualification and the establishment of an adequate institutional framework that contributes to economic development. It is fundamental to the study the acknowledgment that contracts entered into in such financings are, in fact, mechanisms that allow for the operationalization of a given risk allocation structure which, in turn, reflects the project's economic and financial rationale, therefore assuring its bankability. Accordingly, even though each contract conserves its structural autonomy and plays its own economic and social function, they all simultaneously contribute towards the achievement of a further concrete goal - an underlying economic transaction -, identified with the development and operation of the financed venture. Nonetheless, it intends to offer subsidies so that those called upon to decide issues related to the subject can fulfill their duties in an argumentative and coherent manner, without neglecting project finance's underlying economic and legal motivations.
\end{abstract}

Keywords: Project finance. Connected contracts. Project financing. Nexus of contracts. 


\section{INTRODUÇÃO}

Ao longo da década de 1990, verificou-se, de forma intensa e ao redor do globo, um movimento de transição, partindo de um modelo no qual o financiamento exclusivamente público de grandes projetos de infraestrutura restava predominante - especialmente, na década de 1970 - para um modelo no qual o desenvolvimento, construção e operação de tais projetos passaram a contar com a presença do capital privado ${ }^{1}$.

Esta alternância gradativa se deu por um plexo de razões diferentes, mas complementares, usualmente relacionadas (i) à baixa eficiência então associada à gestão pública de tais empreendimentos; (ii) aos problemas orçamentários enfrentados por vários países que, por vezes, eram aqueles que verificavam uma maior precariedade de infraestrutura; e (iii) à dificuldade de captação de recursos a taxas de juros atrativas, por meio dos mercados de capitais, da privatização ou da concessão de serviços públicos.

Nesta linha, a modalidade de financiamento de projetos denominada, na literatura e na prática, de project finance, apresentou-se como importante instrumento para viabilizar o custeio e desenvolvimento dos tão necessários projetos de infraestrutura, possibilitando o fluxo de capital exigido para alavancar os propósitos de crescimento e desenvolvimento de muitas nações ${ }^{2}$.

Esta estrutura envolve, naturalmente e ao contrário do que uma interpretação (e tradução) literal de sua nomenclatura sugere, mais que o simples financiamento de determinado projeto. Na verdade, o project finance desenvolveu-se como um complexo arranjo financeiro e jurídico, cuja utilização é possível em um amplo espectro de empreendimentos.

De forma simples, trata-se de modalidade de financiamento nonrecourse ou limited recourse, predicada nos méritos do projeto financiado, não nas características particulares das organizações patrocinadoras. Aqui, as análises de crédito realizadas pelos financiadores apoiam-se nos fluxos de caixa subjacentes, a serem gerados por meio da execução dos contratos do projeto.

\footnotetext{
${ }^{1}$ Cf. BERTOLETTI, Maria Edith; CUNHA, Rodrigo Ferraz P. Project finance in Brazil: brief analysis of political and collateral risk mitigation, International Business Lawyer, v. 59, 2004, p. 59.

${ }^{2}$ Ibidem, p. 59. Aliás, este foi, exatamente, o caso do Brasil. Sobre tal aspecto, assim apontam os autores, à p. 60: "In this scenario [que há pouco descrevemos], the insufficiency of funds by the Brazilian Government to sponsor infrastructure projects in general and the increase in the international flow of capital are leading to an increase in the demand for private funding from domestic and, more frequently, foreign sources".

Um dos primeiros olhares a respeito da utilização do project finance em nosso país, sob a perspectiva dos bancos públicos, foi lançado por BORGES, Luiz Ferreira Xavier. Project Finance e infra-estrutura: descrição e críticas, Revista do BNDES, v. 5, no 9, 1996, pp. 113, 116-117.
} 
Aliás, uma vez que a habilidade do empreendimento de gerar receitas decorrentes de sua operação ocupa posição fulcral em todo project finance, os instrumentos contratuais constituem o panorama que permite a viabilização do projeto, bem como a adequada alocação dos variados riscos que sobre ele incidem, em uma arquitetura racional dos pontos de vista econômico-financeiro e jurídico ${ }^{3}$.

Como operação compósita que é, esta modalidade de financiamento reflete, perfeitamente, a crescente complexidade das relações econômicas e negociais das quais, necessariamente, tem de tomar conta o Direito. Para a disciplina destas, sabe-se, a consideração hermética e isolada das figuras contratuais muitas vezes revela-se insuficiente, pelo que o tráfego comercial aconselha ou injunge, conforme o caso, a organização de uma agenda contratual composta por instrumentos interligados ${ }^{4}$.

Dentre outros arranjos nos quais os instrumentos contratuais revelam-se, em alguma medida, conectados, encontra-se a coligação contratual. De modo mais específico, contratos coligados podem ser definidos como aqueles que, "por força de disposição legal, da natureza acessória de um deles ou do conteúdo contratual (expresso ou implícito), encontram-se em relação de dependência unilateral ou recíproca"5.

Haja vista que o fenômeno da coligação pode se apresentar, na vida negocial, sob as mais variadas tonalidades, aparecendo, aqui e ali, em maior ou menor intensidade, se revela pouco útil - ou, talvez, até mesmo impossível - precisar, em rol taxativo, todas as consequências jurídicas que dela são consectárias. No entanto, certo é que haverá, em todo caso, uma tal relação de dependência mínima, que irradiará efeitos (i) na interpretação; (ii) na qualificação; (iii) na derrogação de regime jurídico típico; (iv) no plano da validade; e (v) no plano da eficácia.

Nestas relações comerciais complexas, por vezes organizadas em coligação contratual e que ganham cada vez mais oxigenação nos tempos atuais, parte importante do processo negocial diz respeito à identificação de uma estrutura de distribuição dos variados riscos

\footnotetext{
${ }^{3}$ Cf. HOFFMAN, Scott L. A practical guide to transactional project finance: basic concepts, risk identification, and contractual considerations, The Business Lawyer, v. 45, $\mathrm{n}^{\circ}$ 1, 1989, p. 183.

${ }^{4}$ Cf. CORDEIRO, António Menezes. Direito comercial, $3^{\mathrm{a}}$ ed., Coimbra: Almedina, 2012, p. 537. No mesmo sentido, veja-se a assertiva de P. A. Forgioni, apoiada na atemporal construção de C. do Couto e Silva: "Essa concepção [da obrigação como sucessão de fases que visa à satisfação dos interesses do credor] pode e deve ser aplicada aos contratos empresariais, especialmente àqueles dotados de maior grau de complexidade, que carregam consigo uma miríade de disposições contratuais e obrigações, explícitas e implícitas, inter-relacionadas e interdependentes entre si e que assumem sentido quando vistas em sua globalidade e dinâmica. Gravitam, todas elas, em torno dos escopos almejados por ambas as partes, i. e., da operação econômica que encetaram". Cf. Contratos empresariais: teoria geral e aplicação, $2^{\mathrm{a}}$ ed., São Paulo: Revista dos Tribunais, 2016, p. 20.

${ }_{5}^{5}$ Cf. MARINO, Francisco Paulo de Crescenzo. Contratos coligados no direito brasileiro, São Paulo: Saraiva, 2009, p. 99.
} 
incidentes sobre a operação entre os agentes econômicos envolvidos. Esta distribuição, sublinharemos no trabalho, pretendem as partes concebê-la de maneira ótima do ponto de vista econômico-financeiro - isto é, em uma perspectiva de vantagens comparativas para implementação de medidas de controle e gestão do risco - significando que tal ou qual risco deverá ser suportado pela parte que o puder fazer a um menor custo associado.

A tal propósito, é, de fato, indispensável o papel desempenhado pelos contratos. Como verdadeiros instrumentos de alocação de riscos, é por meio deles que os participantes de um programa de project finance poderão desenvolver a operação econômica subjacente de maneira racional, garantindo, notaremos adiante, a própria viabilidade do projeto.

Assim, precisamente nesta intersecção é que se encontra nosso principal problema de pesquisa. Se, de um lado, as multifacetadas operações econômicas que se veem atualmente, das quais são exemplos os financiamentos por project finance, são, muitas vezes, organizadas por meio do recurso a sofisticados entrelaçamentos de contratos, como a coligação contratual, e, de outro, se destes últimos decorrem consequências jurídicas de importância inafastável, parecenos relevante qualificar, de forma justificada e técnica, o project finance como autêntica coligação contratual que é, com as consequências que serão estudadas ${ }^{6}$.

Além disso, em um contexto mais amplo e apoiando-nos em literatura dedicada à análise da relação entre instituições, organizações e desenvolvimento econômico ${ }^{7}$, lançamo-nos a examinar como a rigorosa compreensão de nossas conclusões com relação ao problema de pesquisa pode, nos casos concretos, colaborar para o estabelecimento de um mercado ${ }^{8}$ e, de

\footnotetext{
${ }^{6}$ Sem destoar da magistralidade habitual, T. Ascarelli pontua que "justamente para uma melhor apreciação dos fenômenos econômicos, é mister o mais rigoroso tecnicismo e que os conceitos dogmáticos constituem, afinal, como que instrumentos de trabalho do jurista, sem os quais não pode este preencher a sua tarefa [...] A teoria que se compraz no desprezo da economia e descuida de examinar o alcance econômico dos institutos jurídicos está longe também da teoria que não pode dispensar o conhecimento da função econômica dos institutos jurídicos". Cf. Panorama do direito comercial, $2^{\text {a }}$ ed., Sorocaba: Editora Minelli, 2007, pp. 152-153.

E, ainda sublinhando o magistério do autor, a lição de P. A. Forgioni, a ressaltar a insuficiência dos extremos de teoria e prática do direito comercial: "Por um lado, há quem propugne um direito comercial puramente prático, como se fosse possível a resolução de complexos problemas empresariais sem lançar mão da dogmática. Por outro, aqueles que condenaram o direito comercial à reclusão em uma torre de marfim, repetindo conceitos que, há muito, não guardam pertinência com nossa realidade, tampouco servem para explicá-la". Cf. Tullio Ascarelli e os contratos de distribuição, Revista Magister de Direito Empresarial, Concorrencial e do Consumidor, v. 2, 2005, p. 11.

7 Veja-se, por tudo, NORTH, Douglass C. Institutions, institutional change and economic performance, Cambridge: Cambridge University Press, 1990.

${ }^{8} \mathrm{O}$ mercado deve ser compreendido como ordem, no sentido de regularidade e previsibilidade de agir. Como tal, é formatado pelas normas jurídicas, de sorte a não existir nenhum mercado, determinado no tempo e espaço, que não pressuponha a existência institutos jurídicos - ou, como quiseram P. A. Forgioni e M. Torre-Schaub, o desenvolvimento do mercado "dar-se-á nos espaços deixados pelas regras jurídicas", nos ensinando, a história do Direito e das sociedades, "que la mise en place des structures de l'échange a été marquée par l'adoption de dispositifs normatifs". Cf., respectivamente, A evolução do direito comercial brasileiro: da mercancia ao mercado, $3^{\mathrm{a}}$ ed., São Paulo: Revista dos Tribunais, 2016, p. 144 e Essai sur la construction juridique de la catégorie de marché, Paris: LGDJ, 2002, p. 1. Na dicção de N. Irti: "Nessuno dubita che il mercato sia un ordine
} 
forma mais genérica, de um ambiente mais favorável aos negócios que, inclusive, permita ao Poder Público satisfazer, de forma profusa e eficiente, necessidades essenciais de seus administrados.

Para tanto, o trabalho se organiza da seguinte maneira.

O primeiro capítulo é dedicado à discussão detalhada - mas, seguramente, sem qualquer pretensão exaustiva -, dos principais aspectos, características e conceitos relacionados aos financiamentos por project finance. Como, em nossa opinião, a dogmática jurídica (e, até mesmo, aquela própria da ciência das finanças e da economia) se dedicou de forma muito rasa à produção de um texto mais ou menos consolidado sobre o tema, vimos como relevante este esforço, se nos é permitido afirmar, compilatório 9.

No segundo capítulo, apresentamos as bases conceituais e o estado mais recente da dogmática jurídica que explora o tema da coligação contratual. Limitando-nos a algumas poucas digressões históricas, o propósito central, aqui, é apresentar o ferramental para que se possa assimilar questões tais como (i) do que se trata o fenômeno, distinguindo-lhe de situações vizinhas; (ii) por que é possível afirmar sua relevância do ponto de vista jurídico; (iii) como identificá-lo; e (iv) quais as principais consequências que dele decorrem.

A terceira sessão principia assentada em um debate a respeito dos contratos como mecanismos de alocação de riscos, passando, após, à análise da estrutura contratual "típica" dos financiamentos dos quais nos ocupamos.

A quarta parte do estudo estabelece o elo entre as três primeiras, tendo como ponto nevrálgico, de fato, a qualificação das operações de project finance como coligação contratual, investigando algumas das consequências jurídicas que daí seguem e apresentando as poucas abordagens da temática pela dogmática e jurisprudência.

O quinto e último capítulo lança luz sobre a importância dos investimentos em infraestrutura, da participação do capital privado nesta arena e, mais especificamente, relaciona como o project finance - e a correta compreensão de seus fundamentos, de sua racionalidade subjacente e de sua arquitetura jurídica - pode contribuir para o desenvolvimento econômico de uma nação.

[...] Ordine, nel senso di regolarità e prevedibilità dell'agire [...] La regolarità, il reiterarsi di dati comportamenti nelle medesime circostanze, permette un calcolo sul futuro, quel 'pre-vedere', o vedere prima, onde un soggetto confida nell'agire altrui'. Cf. L'ordine giuridico del mercato, $5^{\text {a }}$ ed., Roma: Laterza, 2003, pp. VII, 4-5. Nesta acepção é que tomaremos o termo mercado ao longo do trabalho, sem descurar, contudo, de sua acertada compreensão como "fenômeno poliédrico". Sobre este último ponto, cf. FORGIONI, Paula Andrea. A evolução do direito comercial, cit., pp. 135 e ss.

${ }^{9}$ É preciso excetuar, neste tocante, a excelente monografia de J. V. L. Enei, Financiamento de projetos: aspectos jurídicos do financiamento com foco em empreendimentos, Dissertação de Mestrado, Universidade de São Paulo, São Paulo, 2005. 


\section{CONCLUSÃO}

O presente trabalho tomou, como hipótese de pesquisa, a qualificação dos diversos contratos usualmente celebrados em operações de project finance como verdadeira coligação contratual. Partindo daí, foram derivadas consequências jurídicas que se apresentam em matéria de interpretação dos contratos, qualificação e derrogação de regime jurídico, plano da validade e plano da eficácia. Já em tom de fechamento, associou-se, de um lado, a compreensão da coligação e, de outro, o estabelecimento de um adequado panorama institucional que contribua, em última instância, para o desenvolvimento econômico.

Acreditamos que a hipótese suscitada fora comprovada, na medida em que se tornou evidente o fato de que os variados contratos celebrados ao longo das agendas de financiamento examinadas não podem ser compreendidos como uma pluralidade de negócios desvinculada, mas, antes, como um programa de contratos coligados - no qual ocupa posição central o contrato de crédito -, unidos por um nexo finalístico, orientados, todos eles, à consecução da operação econômica subjacente.

Portanto, se é certo que os negócios conservam sua autonomia estrutural, exercendo ainda, cada um, o resultado econômico-social que deles se espera, a apresentação de um fim concreto, coincidente com o desenvolvimento e operação do projeto, em consonância com a estrutura de alocação de riscos concebida e acordada contratualmente, e trabalhando como um norte, impõe ao intérprete determinados compromissos inarredáveis.

Tais incumbências incluem, dentre outras, (i) a necessária interpretação global dos contratos; (ii) o reconhecimento do surgimento de relações jurídicas envolvendo personagens que não permanecem adstritas à noção tradicional de "partes" (que, então, poderá autorizar a aplicação de remédios sinalagmáticos e a oposição de inadimplemento de "terceiros"); (iii) o distanciamento, estrutural ou funcional, de determinado negócio em concreto com relação ao quadro normal, estabelecido em lei, justificando, portanto, a derrogação de seu regime jurídico típico (como é o caso do contrato de O\&M); (iv) o prestígio à regra geral de instabilidade do fim concreto frente à invalidade ou ineficácia de um dos contratos do project finance, acarretando, no mais das vezes, a ineficácia superveniente dos demais; e (v) a relativização da natureza acessória dos contratos de garantia, que assumem papel de verdadeiros protetores do sistema.

O reconhecimento da situação de coligação - notada, ainda, a substancial diferença entre esta última e, por exemplo, as redes de contratos - vai de encontro ao rigor científico que 
se exige da dogmática e não pretende ser estéril, como que afeito a um hipotético preciosismo teórico.

Ao contrário, pensamos, somente por meio deste engajamento firme é que aqueles chamados a decidir sobre a matéria, em sede arbitral ou judicial, terão, à sua disposição, substratos que oportunizem construções tecnicamente coerentes, conferindo, aos agentes, segurança e a tão exigida calculabilidade, estabelecendo-se, assim, instituições formais eficientes, que reduzam os custos de transação e contribuam para o azeitamento das relações econômicas e, igualmente, propiciem saltos estruturais qualitativos na condição de vida dos cidadãos.

Estamos certos de que não se esvaem os caminhos para a pesquisa no tema. Ao revés, partindo da premissa aqui central, ao estudioso se pronunciarão outras - e, então, renovadas problemáticas, que serão, seguramente, merecedoras de atenção por parte da ciência do Direito. 


\section{REFERÊNCIAS}

ALVIM, Tiago Cripa. Project finance, concessões e PPPs. In: CARVALHO, André Castro; CASTRO, Leonardo Freitas de Moraes e (coord.). Manual de Project Finance no Direito Brasileiro, São Paulo: Quartier Latin, 2016, pp. 67-99.

ARAÚJO, Fernando. Teoria económica do contrato, Coimbra: Almedina, 2007.

ARMOUR, John; HERTIG, Gerard; KANDA, Hideki. Transactions with creditors. In: The anatomy of Corporate Law: a comparative and functional approach, $2^{\mathrm{a}}$ ed., Oxford: Oxford University Press, 2009, pp. 115-151.

ASCARELLI, Tullio. Panorama do direito comercial, 2a ed., Sorocaba: Editora Minelli, 2007.

AZARA, Antonio; EULA, Ernesto; SCARELLA, Dante. Novissimo digesto italiano, Torino: Editrice Torinese, 1986.

AZEVEDO, Antônio Junqueira de. Negócio jurídico: existência, validade e eficácia, São Paulo: Saraiva, 2008.

Negócio jurídico e declaração negocial: noções gerais e formação da declaração negocial, Tese (titular), Universidade de São Paulo, São Paulo, 1986.

BACACHE-GIBEILI, Mireille. La relativité des conventions et les groupes de contrats, Paris: LGDJ, 1996.

BARRERA, Ligia Catherine Arias. Perspectiva legal de la financiación de proyectos "Project Finance" y el manejo del riesgo, Revista de Derecho Privado, n 23, 2012, pp. 211-243.

BERLE, Adolf; MEANS, Gardiner. The modern corporation and private property, New York: The Mac-Millan Company, 1932.

BERTOLETTI, Maria Edith; CUNHA, Rodrigo Ferraz P. Project finance in Brazil: brief analysis of political and collateral risk mitigation, International Business Lawyer, v. 59, 2004, pp. 59-61. 
BETTI, Emilio. Teoria generale del negozio giuridico, ristampa correta della II edizione, Napoli: Edizioni Scientifiche Italiane, 1994.

BIANCA, Cesare Massimo. Diritto civile, v. 3, Milano: Giuffrè, 2000.

BONETTI, Veronica; CASELLI, Stefano; GATTI, Stefano. Offtaking agreements and how they impact the cost of funding for project finance deals: a clinical case study of the Quezon Power Ltd Co, Review of Financial Economics, v. 19, 2010, pp. 60-71.

BONOMI, Claudio A.; MALVESSI, Oscar. Project finance no Brasil: fundamentos e estudos de casos, $3^{\mathrm{a}}$ ed., São Paulo: Atlas, 2008.

BORGES, Luiz Ferreira Xavier. A teoria da desconsideração da personalidade jurídica e sua aplicação em análise de crédito, Revista do BNDES, v. 7, nº 14, 2000, pp. 329-350.

Covenants: instrumento de garantia em Project Finance, Revista do BNDES, v. 6, $\mathrm{n}^{\circ}$ 11, 1999, pp. 117-135.

Project Finance e infra-estrutura: descrição e críticas, Revista do BNDES, v. 5, nº 9, 1998, pp. 105-121.

BREALEY, Richard A.; COOPER, Ian A.; HABIB, Michael A. Using project finance to fund infrastructure investments, Journal of Applied Corporate Finance, v. 9, 1996, pp. 25-38.

CARMO, Lie Uema do. Contratos de construção de grandes obras, Tese de Doutorado, Universidade de São Paulo, São Paulo, 2012.

CARVALHOSA, Modesto. Comentários à lei de sociedades anônimas, $5^{\text {a }}$ ed., v. 1, São Paulo: Saraiva, 2009.

Acordo de acionistas, $2^{\mathrm{a}}$ ed., São Paulo: Saraiva, 2015.

COLOMBO, Claudio. Operazioni economiche e collegamento negoziale, Padova: CEDAM, 1999.

COMPARATO, Fábio Konder. Aspectos jurídicos da macro-emprêsa, São Paulo: Revista dos Tribunais, 1970 . 
COMPARATO, Fábio Konder; FILHO, Calixto Salomão. O poder de controle na sociedade anônima, $6^{\mathrm{a}}$ ed., Rio de Janeiro: Forense, 2014.

CORDEIRO, António Menezes. Direito comercial, 3ª ed., Coimbra: Almedina, 2012.

CORIELLI, Francesco; GATTI, Stefano; STEFFANONI, Alessandro. Risk shifting through nonfinancial contracts: effects on loan spreads and capital structure of project finance deals, Journal of Money, Credit and Banking, v. 42, nº 7, 2010, pp. 1.295-1.320.

DAILAMI, Mansoor; LEIPZIGER, Danny. Infrastructure Project Finance and capital flows: a new perspective, World Development, v. 26, nº 7, 1998, pp. 1.283-1.298.

DAMODARAN, Aswath. Applied corporate finance, $4^{\mathrm{a}}$ ed., Hoboken: John Wiley \& Sons, 2014.

DEMO, Pedro. Cuidado metodológico: signo crucial de qualidade, Sociedade e Estado, v. 7, no 2, 2002, pp. 349-373.

DE NARDI, Marcelo. Redes de contratos em perspectiva de interpretação sistêmica, Porto Alegre: Verbo Jurídico, 2015.

DE NOVA, Giorgio. Il tipo contrattuale, Padova: CEDAM, 1974.

DE MIRANDA, Luiz Ricardo. O Grupo Banco Mundial e a regulação internacional do financiamento de projetos (Project Finance), Tese de Doutorado, Universidade de São Paulo, São Paulo, 2013.

DEWAR, John. International project finance: law and practice, Oxford: Oxford University Press, 2011.

DINIZ, Gustavo Saad. Dependência econômica nos acordos verticais, Revista de Direito Privado, v. 59, 2014, pp. 91-120. . Instrumentos de capitalização societária, São Paulo: LiberArs, 2014. . Subcapitalização societária: financiamento e responsabilidade, Belo Horizonte: Fórum, 2012. 
DINTHILHAC, Clio; RUIZ-NUÑEZ, Fernanda; WEI, Zichao. The economic impact of infrastructure and public-private partnerships: literature review, World Bank Group Working Papers, 2015.

DJANKOV, Simeon et al. Courts, Quarterly Journal of Economics, v. 118, nº 2, 2003, pp. 453517.

ENEI, José Virgílio Lopes. Contratos coligados, Revista de Direito Mercantil, Industrial, Econômico e Financeiro, v. 132, 2003, pp. 111-128.

. Financiamento de projetos: aspectos jurídicos do financiamento com foco em empreendimentos, Dissertação de Mestrado, Universidade de São Paulo, São Paulo, 2005.

ENNECCERUS, Ludwig. Tratado de derecho civil, tomo 2, v. 3, Barcelona: Bosch, 1935.

ESTACHE, Antonio; GARSOUS, Grégoire. The impact of infrastructure on growth in developing countries, IFC Economic Notes, $\mathrm{n}^{\circ}$ 1, 2012.

ESTY, Benjamin C. Modern project finance: a casebook, Hoboken: John Wiley \& Sons, 2004. Petrozuata: a case study of the effective use of Project Finance, Journal of Applied Corporate Finance, v. 12, 1999, pp. 26-42.

The economic motivations for using project finance, Harvard Business School, 2003.

Why study large projects? An introduction to research on Project Finance, European Financial Management, v. 10, $\mathrm{n}^{\circ}$ 2, 2004, pp. 213-224.

ESTY, Benjamin C.; MEGGINSON, William L. Legal risk as a determinant of syndicate structure in the project finance loan market, Harvard Business School, 2001.

Syndicate structure as a response to political risk in the project finance loan market, Harvard Business School, 2001.

FABOZZI, Frank; DE NAHLIK, Carmel. Project financing, $8^{\mathrm{a}}$ ed., London: Euromoney Books, 2012.

FERRI, Giuseppe. Manuale di diritto commerciale, 12 ed., Torino: UTET Giuridica, 2006. 
FERRO, Murilo Ruiz. A relação entre PPPs e Project Finance à luz do cenário e do Direito da Infraestrutura no Brasil. In: CARVALHO, André Castro; CASTRO, Leonardo Freitas de Moraes e (coord.). Manual de Project Finance no Direito Brasileiro, São Paulo: Quartier Latin, 2016, pp. 119-139.

FIGHT, Andrew. Introduction to project finance, Burlington: Butterworth-Heinemann, 2006.

FINNERTY, John D. Project financing: asset-based financial engineering, $2^{\mathrm{a}}$ ed., Hoboken: John Wiley \& Sons, 2007.

FORGIONI, Paula Andrea. A evolução do direito comercial brasileiro: da mercancia ao mercado, $3^{\mathrm{a}}$ ed., São Paulo: Revista dos Tribunais, 2016.

A interpretação dos negócios empresariais no Novo Código Civil Brasileiro, Revista de Direito Mercantil, Industrial, Econômico e Financeiro, v. 42, 2003, pp. 7-38.

Análise econômica do direito (AED): paranóia ou mistificação?, Revista de Direito Mercantil, Industrial, Econômico e Financeiro, v. 139, 2005, pp. 242-256.

Apontamentos sobre algumas regras de interpretação dos contratos comerciais: Pothier, Cairu e Código Comercial de 1850, Revista de Direito Mercantil, Industrial, Econômico e Financeiro, v. 141, 2006, pp. 31-59.

Contratos empresariais: teoria geral e aplicação, $2^{\text {a }}$ ed, São Paulo: Revista dos Tribunais, 2016.

- Tullio Ascarelli e os contratos de distribuição, Revista Magister de Direito Empresarial, Concorrencial e do Consumidor, v. 2, 2005, pp. 11-35.

FRÍAS, Ana López. Los contratos conexos: estudio de supuestos concretos y ensayo de una construcción doctrinal, Barcelona: Bosch, 1994.

GABRIELLI, Enrico. Alea e rischio nel contratto - Studi, Napoli: Esi, 1997.

GALA, Paulo. A teoria institucional de Douglass North, Revista de Economia Política, v. 23, nº 2, 2003, pp. 89-105. 
GARNER, Bryan A. Black's law dictionary, 9a ed., St. Paul: Thomson West, 2009.

GATTI, Stefano. Project finance in theory and practice: designing, structuring and financing private and public projects, $2^{\mathrm{a}}$ ed., Waltham: Elsevier, 2013.

GOLDBERG, Victor P. Risk management in long-term contracts, Columbia Law School Working Papers, $\mathrm{n}^{\mathrm{o}}$ 282, 2005.

GOMES, Orlando. Contratos, 22a ed., Rio de Janeiro: Forense, 2008.

GORTON, Gary B.; SOULELES, Nicholas S. Special purpose vehicles and securitization. In: CAREY, Mark; STULZ, René M. (ed.). The risks offinancial institutions, Chicago: University of Chicago Press, 2007, pp. 549-602.

GRAU, Eros Roberto. A ordem econômica na Constituição de 1988, 14ª ed., São Paulo: Malheiros, 2010.

GUIMARÃES, Leonardo. A SPE - Sociedade de propósito específico, Revista de Direito Mercantil, Industrial, Econômico e Financeiro, v. 125, 2002, pp. 129-137.

GUSTIN, Miracy Barbosa de Sousa; DIAS, Maria Tereza Fonseca. Repensando a pesquisa jurídica, Belo Horizonte: Del Rey, 2015.

HAACK, Susan. Philosophy of logics, Cambridge: Cambridge University Press, 1978.

HADFIELD, Gillian K. The many legal institutions that support contractual commitments. In: MÉNARD, Claude; SHIRLEY, Mary M. (ed.). Handbook of new institutional economics, Berlin: Springer-Verlag, 2008, pp. 175-203.

HARFORD, Jarrad. Corporate cash reserves and acquisitions, Journal of Finance, v. 54, nº 6 , 1999, pp. 1.969-1.997.

HARRIS, Clive. Private participation in infrastructure in developing countries: trends, impacts, and policy lessons, World Bank Working Papers, 2003.

HOFFMAN, Scott L. A practical guide to transactional project finance: basic concepts, risk identification, and contractual considerations, The Business Lawyer, v. 45, nº 1, 1989, pp. 181232. 
The law and business of international project finance, $2^{\mathrm{a}}$ ed., Ardsley: Transnational Publishers, 2001.

HOWCROFT, Barry; FADHLEY, Sabah. Project finance: a credit strategy based on contractual linkages, The Service Industries Journal, v. 18, nº 2, 1998, pp. 90-111.

IRTI, Natalino. L'ordine giuridico del mercato, $5^{\mathrm{a}}$ ed., Roma: Laterza, 2003.

ITURRASPE, Jorge Mosset. Como contratar en una economía de mercado, Buenos Aires: Rubinzal-Culzoni, 1996.

JENSEN, Michael C.; MECKLING, William H. Theory of the firm: managerial behavior, agency costs, and ownership structure, Journal of Financial Economics, v. 3, nº 4, 1976, pp. 305-360.

JENSEN, Michael C. Agency costs of free cash flow, corporate finance, and takeovers, American Economic Review, v. 76, n² 2, 1986, pp. 323-329.

JOSKOW, Paul L. Vertical integration and long-term contracts: the case of coal-burning electric generating plants, Journal of Law, Economics and Organizations, v. 1, 1985, pp. 3380.

KATAOKA, Eduardo T. A coligação contratual, Rio de Janeiro: Lumen Juris, 2008.

KABIR KHAN, Fouzul; PARRA, Robert J. Financing large projects using project finance techniques and practices, Singapore: Prentice Hall, 2003.

KLEIMEIER, Stefanie; VERSTEEG, Roald. Project finance as a driver of economic growth in low-income countries, Review of Financial Economics, v. 19, 2010, pp. 49-59.

KONDER, Carlos N. Contratos conexos: grupos de contratos, redes contratuais e contratos coligados, Rio de Janeiro: Renovar, 2006.

LA COUR, Lisbeth F.; MÜLLER, Jennifer. Growth and project finance in the least developed countries, International Journal of Economic Sciences and Applied Research, v. 7, 2014, pp. 77-103. 
LARENZ, Karl. Metodologia da ciência do direito, $7^{\mathrm{a}}$ ed., Lisboa: Fundação Calouste Gulbenkian, 2014.

LEÃES, Luiz Gastão Paes de Barros. Pareceres, v. 2, São Paulo: Editora Singular, 2004.

LEONARDO, Rodrigo Xavier. Redes contratuais no mercado habitacional, São Paulo: Revista dos Tribunais, 2003.

LEVINE, Ross. Law, finance and economic growth, Journal of Financial Intermediation, v. 8, 1999, pp. 8-35.

LEWELLEN, Wilbur G. A pure financial rationale for the conglomerate merger, Journal of Finance, v. 26, n 2, 1970, pp. 521-537.

LENER, Giorgio. Profili del collegamento negoziale, Milano: Giuffrè, 1999.

LORENZETTI, Ricardo Luis. Tratado de los contratos, tomo 1, Buenos Aires: RubinzalCulzoni, 1999.

MARINO, Francisco Paulo de Crescenzo. Contratos coligados no direito brasileiro, São Paulo: Saraiva, 2009.

MARQUES, Claudia Lima. Contratos no Código de Defesa do Consumidor: o novo regime das relações contratuais, $6^{\text {a }}$ ed., São Paulo: Revista dos Tribunais, 2011.

MARTINO, Luiz C.; BOAVENTURA, Katrine Tokarski. O mito da interdisciplinariedade: história e institucionalização de uma ideologia, Revista da Associação Nacional dos Programas de Pós-Graduação em Comunicação | E-compós, v. 16, nº 1, jan/abr 2013, pp. 1-16.

MARTINS, Fran; DINIZ, Gustavo Saad. Contratos e obrigações comerciais, $17^{\mathrm{a}}$ ed., v. 1, Rio de Janeiro: Forense, 2016.

MEIRELLES, Hely Lopes. Direito administrativo brasileiro, 24a ed., São Paulo: Malheiros, 1999.

MENDES, Rodrigo Octávio Broglia. A empresa em rede: a empresa virtual como mote para reflexão no Direito Comercial, Revista do Advogado, v. 115, 2012, pp. 129-135. 
MEOLI, Bruno. I contratti collegati nelle esperienze giuridiche italiana e francese, Napoli: Edizioni Scientifiche Italiane, 1999.

MESSINEO, Francesco. Contratto collegato (verbete). In: Enciclopedia del diritto, tomo X, Milano: Giuffrè, 1962, pp. 48-54.

MIYAMOTO, Ken. Measuring legal risk premium in project finance bonds, Virginia Journal of International Law, v. 40, 1999-2000, pp. 1.125-1.154.

MODIGLIANI, Franco; MILLER, Merton. The cost of capital, corporation finance and the theory of investment, American Economic Review, v. 48, nº 3, 1958, pp. 261-297.

MORAES, Luiza Rangel de. Considerações sobre BOT - Project finance e suas aplicações em concessões de serviços públicos, Revista de Direito Administrativo, v. 212, 1998, pp. 135-150.

MOREIRA, Egon Bockmann. Concessões de serviços públicos e project finance, Revista Eletrônica de Direito Administrativo Econômico, nº 23, 2010, pp. 1-10.

MORILLO, Fernanda; BORDONS, María; GÓMEZ, Isabel. Interdisciplinarity in science: a tentative typology of disciplines and research areas, Journal of the American Society for Information Science and Technology, v. 54, 2003, pp. 1.237-1.249.

MOURÃO, Mario. Financiamentos estruturados, São Paulo: Almedina, 2016.

MOUTIER, Michel Lyonnet du. Financement sur projet: elaboration d'un test de la théorie positive de l'agence, Finance Contrôle Stratégie, v. 7, nº 3, 2004, pp. 147-168.

MOUZAS, Stefano; FURMSTON, Michael. From contract to umbrella agreement, The Cambridge Law Journal, v. 67, 2008, pp. 37-50.

MURATORI, Filippo. Riflessioni su taluni aspetti giuridici significativi del project finance. In: Responsabilità, comunicazione, impresa, v. 3-4, Milano: Giuffrè, 1996, pp. 509-530.

MYERS, Stewart C. Determinants of corporate borrowing, Journal of Financial Economics, v. 5, 1977, pp. 147-175.

NORTH, Douglass C. Institutions and economic growth: an historical introduction, World Development, v. 17, $\mathrm{n}^{\circ}$ 9, 1989, pp. 1319-1332. 
Institutions, Journal of Economic Perspectives, v. 5, nº 1, 1991, pp. 97-112.

. Institutions, institutional change and economic performance, Cambridge: Cambridge University Press, 1990.

NORTH, Douglass C. et al. Limited access orders in the developing world: a new approach to the problems of development, World Bank Policy Research Working Paper, no 4359, 2007.

NUSDEO, Fábio. Curso de economia: introdução ao direito econômico, $7^{\mathrm{a}}$ ed., São Paulo: Revista dos Tribunais, 2013.

PELLÉ, Sébastien. La notion d'interdépendance contractuelle: contribution à l'étude des ensembles de contrats, Paris: Dalloz, 2007.

PENTEADO, Luciano de Camargo. Direito das coisas, $2^{\mathrm{a}}$ ed., São Paulo: Revista dos Tribunais, 2012.

. Efeitos contratuais perante terceiros, São Paulo: Quartier Latin, 2007.

Redes contratuais e contratos coligados. In: HIRONAKA, Giselda; TARTUCE, Flavio (coord.). Direito contratual - temas atuais, $1^{\text {a }}$ ed., v. 1, São Paulo: Método, 2007, pp. 463-492.

PERLINGIERI, Pietro. Normas constitucionais nas relações privadas, Revista da Faculdade de Direito da UERJ, nºs. 6-7, 1998-1999, pp. 63-77.

Perfis do direito civil: introdução ao direito civil constitucional, trad. M. C. de Cicco, Rio de Janeiro: Renovar, 1999.

PINHEIRO, Armando Castelar; SADDI, Jairo. Direito, economia e mercados, Rio de Janeiro: Elsevier, 2006.

PONTES DE MIRANDA, Francisco Cavalcante. Tratado de direito privado, tomo III, Campinas: Bookseller, 2001.

PRETORIUS, Frederik et. al. Project finance for construction \& infrastructure: principles \& case studies, Oxford: Blackwell Publishing, 2008. 
RABITTI, Gian Luca. Project finance e collegamento contrattuale. In: Contratto e impresa, Padova: CEDAM, 1996, pp. 223-252.

RAPAZZO, Antonio. I contratti collegati, Milano: Giuffrè, 1998.

RAUNER, Stewart E. Project finance: a risk spreading approach to the commercial financing of economic development, Harvard International Law Journal, v. 24, 1983, pp. 145-181.

RIBEIRO, Marcia Carla Pereira; AGUSTINHO, Eduardo. Fundamentos para a interpretação dos contratos empresariais: aspectos jurídicos e econômicos, Revista de Direito Mercantil, Industrial, Econômico e Financeiro, v. 151/152, 2009, pp. 65-78.

RIBEIRO, Marcia Carla Pereira; GALESKI JUNIOR, Irineu. Teoria geral dos contratos: contratos empresariais e análise econômica, Rio de Janeiro: Elsevier, 2009.

RIBEIRO, Marcia Carla Pereira; NETO, Rogério Rudiniki. Uma análise da eficiência do Poder Judiciário com base no pensamento de Douglas North, Quaestio Iuris, v. 09, nº 04, 2016, pp. 2.025-2.040.

ROCHA, Lara Bonemer Azevedo da; RIBEIRO, Marcia Carla Pereira. Previsibilidade das decisões judiciais como fator de desenvolvimento, Revista da AJURIS, v. 40, n 32, 2013, pp. 175-178.

A importância do sistema de justiça para o desenvolvimento econômico, Revista Jurídica da Procuradoria-Geral do Estado do Paraná, n 6, 2015, pp. 103-133.

RODRIGUES JUNIOR, Otavio L. Estatuto epistemológico do Direito Civil contemporâneo na tradição de civil law em face do neoconstitucionalismo e dos princípios, O Direito, $\mathrm{n}^{\circ}$ 143, II, 2011, pp. 43-66.

RODRIGUEZ, José Rodrigo. Dogmática jurídica (verbete), Artigos Direito GV (Working Papers), no 36, 2009.

ROPPO, Enzo. O contrato, Coimbra: Almedina, 2009.

ROSITO, Francisco. Os contratos conexos e sua interpretação, Revista de Direito Mercantil, Industrial, Econômico e Financeiro, v. 145, 2007, pp. 85-106. 
ROSS, Stephen A.; WESTERFIELD, Randolph W.; JAFFE, Jeffrey. Corporate finance, $10^{\mathrm{a}}$ ed., New York: McGraw-Hill Irwin, 2012.

RECHTSCHAFFEN, Alan N. Capital markets, derivatives and the law, Oxford: Oxford University Press, 2009.

RUPERTO, Cesare. La giurisprudenza sul Codice Civile coordinata con la dottrina, livro IV, tomo I, Milano: Giuffrè, 2009.

SALAMA, Bruno Meyerhof. Sete enigmas do desenvolvimento em Douglass North, Economic Analysis of Law Review, v. 2, nº 2, 2011, pp. 404-428.

SALOMÃO NETO, Eduardo. Direito bancário, 2a ed., São Paulo: Atlas, 2014.

SALOMÃO NETO, Eduardo; LINS, Paulo Meira. Direito dos financiadores à concessão nas operações de Project Finance. In: KUYVEN, Luiz Fernando Martins. Temas essenciais de direito empresarial: estudos em homenagem a Modesto Carvalhosa, São Paulo: Saraiva, 2012, pp. 296-317.

SALOMON, Délcio Vieira. Como fazer uma monografia, 10ª ed., São Paulo: Martins Fontes, 2001.

SCONAMIGLIO, Renato. Collegamento negoziale (verbete). In: Enciclopedia del diritto, tomo VII, Milano: Giuffrè, 1960, pp. 375-381.

SHAH, Salman; THAKOR, Anjan V. Optimal capital structure and project financing, Journal of Economic Theory, v. 42, 1987, pp. 209-243.

SHEN-FA, Wu; XIAO-PING, Wei. The rule and method of risk allocation in project finance, Procedia Earth and Planetary Science, v. 1, 2009, pp. 1.757-1.763.

SMITH JR., Clifford W. Investment banking and the capital acquisition process, Journal of Financial Economics, v. 15, 1986, pp. 3-29.

STONE, Richard; DEVENNEY, James. The modern law of contract, $11^{\mathrm{a}}$ ed., London: Routledge, 2015. 
SZTAJN, Rachel. Teoria jurídica da empresa, 2ª ed., São Paulo: Atlas, 2010.

TAN, Willie. Principles of project and infrastructure finance, New York: Taylor \& Francis, 2007.

TEUBNER, Gunther. Networks as connected contracts, Oxford: Hart Publishing, 2011.

TEYSSIÉ, Bernard. Les groupes de contrats, Paris: LGDJ, 1975.

TIMM, Luciano Benetti; D’AVILA, Anderson Jardim. Alienação fiduciária em garantia no project finance no Brasil, Revista de Direito Bancário e do Mercado de Capitais, v. 51, 2011, pp. 131-154.

TINSLEY, Richard. Advanced project financing: structuring risks, $2^{\mathrm{a}}$ ed., London: Euromoney Institutional Investor, 2014.

TORRE-SCHAUB, Marthe. Essai sur la construction juridique de la catégorie de marché, Paris: LGDJ, 2002.

TRIANTIS, George G. Contractual allocations of unknown risks: a critique of the doctrine of commercial impracticability, The University of Toronto Law Journal, v. 42, n 4, 1992, pp. 450483.

VARIAN, Hal Ronald. Intermediate microeconomics: a modern approach, $8^{\mathrm{a}}$ ed., New York: W. W. Norton \& Company, 2010.

VINTER, Graham D. Project finance: a legal guide, $2^{\mathrm{a}}$ ed, London: Sweet \& Maxwell, 2003.

VIRGO, Graham. Contract construction and risk allocation, The Cambridge Law Journal, v. $58, \mathrm{n}^{\mathrm{o}} 2,1999$, pp. 273-276.

YESCOMBE, Edward R. Principles of project finance, $2^{\mathrm{a}}$ ed., Waltham: Academic Press, 2013.

ZANCHIM, Kleber Luiz. Intervenção e step-in rights: um conflito de poder entre Administração Pública e Agente Financiador nas Parcerias Público-Privadas Brasileiras, Revista de Direito Mercantil, Industrial, Econômico e Financeiro, v. 144, 2006, pp. 194-207. 